\title{
Algorithm and Design Methodology to Develop a PIFA with Optimized Reflection Coefficient for the ISM 868 MHz Band
}

\author{
Bouchta Hajjine, Christophe Escriba, Daniel Medale, Jean-Yves Fourniols \\ LAAS-CNRS, Université de Toulouse, CNRS, INSA, Toulouse, France \\ Email: bhajjine@laas.fr, cescriba@laas.fr,medale@laas.fr, fourniol@laas.fr
}

How to cite this paper: Hajjine, B., Escriba, C., Medale, D. and Fourniols, J.-Y. (2016) Algorithm and Design Methodology to Develop a PIFA with Optimized Reflection Coefficient for the ISM $868 \mathrm{MHz}$ Band. Open Journal of Antennas and Propagation, 4, 166-175.

http://dx.doi.org/10.4236/ojapr.2016.44013

Received: August 8, 2016

Accepted: November 28, 2016

Published: December 1, 2016

Copyright $\odot 2016$ by authors and Scientific Research Publishing Inc. This work is licensed under the Creative Commons Attribution-NonCommercial International License (CC BY-NC 4.0). http://creativecommons.org/licenses/by-nc/4.0/

cc) (i) (8) Open Access

\begin{abstract}
This paper presents a methodological approach to design a printed Inverted $\mathrm{F}$ antenna for the ISM $868 \mathrm{MHz}$ band. For this design, the ground plane dimensions were kept fixed and the meandered radiating arm was modified to obtain the best compromise integration/performances. This approach was then generalized to design meandered printed inverted $\mathrm{F}$ antennas.
\end{abstract}

\section{Keywords}

Design, Algorithm, Meandered Antenna, PIFA, ISM, Integration, Reflection Coefficient

\section{Introduction}

With the great progress that knows the domain of Human Health Monitoring (HHM), Internet of Things (IoT), and smart homes... more and more miniaturized systems have been developed based on the use of wireless technology for data transmission. The integration of these technologies requires the use of antennas with different frequencies: $868 \mathrm{MHz}$ [1], 2.4 GHz (Zigbee [2], Bluetooth Low Energy [3] ...), 1575.42 MHz [4] (GPS applications)...

This integration process is often confronted with antennas size and bulk problematic explaining the different research works that aim at the development of miniaturized antennas and communicating systems.

Printed antennas are currently the most used type for the different mobile devices; they have a high degree of integration and manufacturing cost included in the PCB one. Among these antennas we have chosen to study a specific one named printed inverted $\mathrm{F}$ 
antenna (PIFA). For this type, several miniaturization techniques can be used such as meandering the radiation arm [5] or adding a supplementary inductive or capacitive load [6]. In this paper, the first method was selected and the functioning frequency was fixed to the ISM $868 \mathrm{MHz}$ band. In this paper, we present a methodological approach to design an antenna with an optimized reflection coefficient. This algorithm describes the different parameters to be taken into account during the design based on integration constraints in a real case related to a research program. The ground plane form was fixed after the routing of the PCB (Printed Circuit Board) and its dimensions should be adequately chosen to ensure acceptable performances for the antenna. The influences of essential parameters were studied such as the distance between the antenna strands, the length of the radiating arm, and the form of the stub. The different steps are described based on ADS RF software to make this paper a simplified guide to design a meandered PIFA. The second section of this paper describes the design methodology of the waveguide and the printed antenna, the third part details the measurements results and finally we present a generalized algorithm to design meandered printed inverted $\mathrm{F}$ antennas.

\section{Design Methodology}

\subsection{Dimensioning of the Waveguide}

Printed antennas are generally used with coplanar waveguides to transfer the received or transmitted signals. As its name indicates, a waveguide helps to guide the electromagnetic waves over a certain distance. It is a special form of transmission line that exists in several formats and can be manufactured using the printed circuit technology. A coplanar waveguide consists of a central conductive line surrounded by the ground plane on both sides of the substrate. Figure 1 presents the geometrical characteristics of a printed waveguide.

The waveguide must present a characteristic impedance of $50 \Omega$ to meet the antenna one. A model that permits to calculate the impedance of the waveguide is presented in [7]. Basing on this model, the variations of the waveguide impedance according to the width of the center line "a" and the distance between the two ground planes "b" are studied in Figure 2 and Figure 3 to choose the adequate dimensions. An FR4 substrate $(\mathcal{E}=4.6)$ and copper tracks with a thickness of $40 \mu \mathrm{m}$ were chosen as example. This is justified by the use of these values in the realization of the PCB presented in this paper.

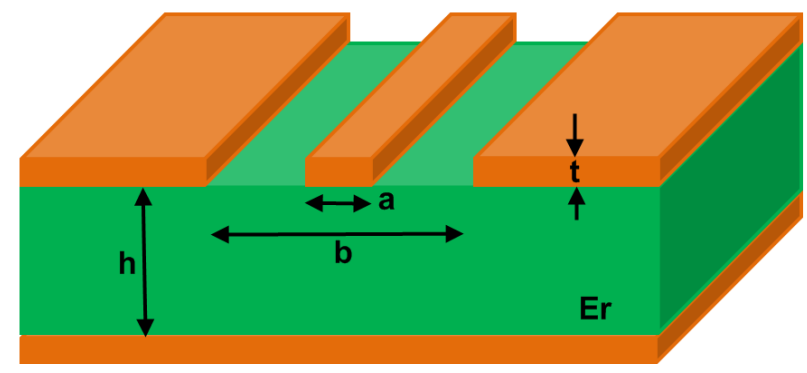

Figure 1. Geometrical characteristics of a coplanar waveguide. 


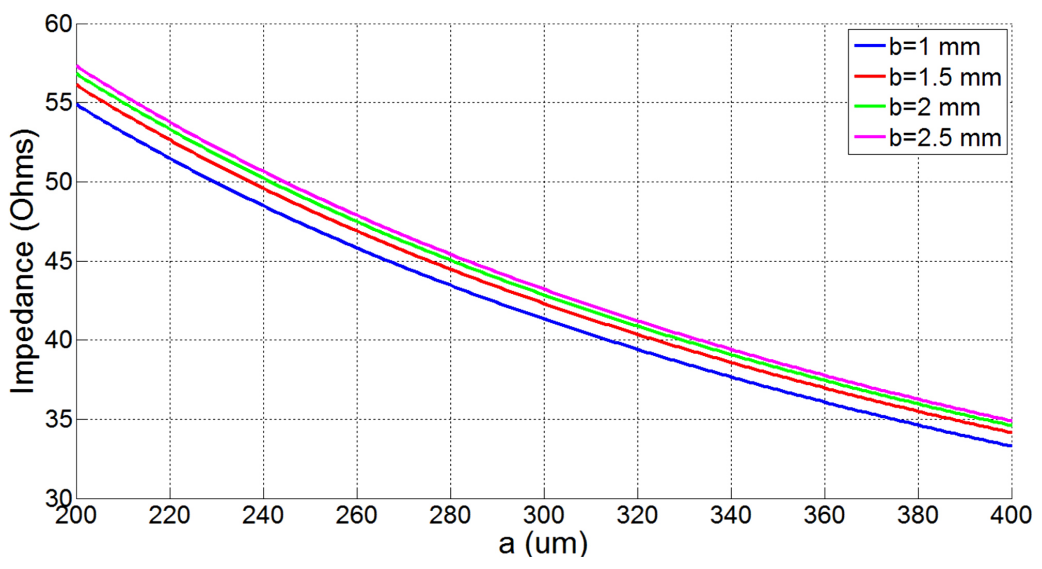

Figure 2. Waveguide impedance variations according to "a" ( $\mathrm{t}=40 \mu \mathrm{m}, \mathrm{h}=120 \mu \mathrm{m})$.

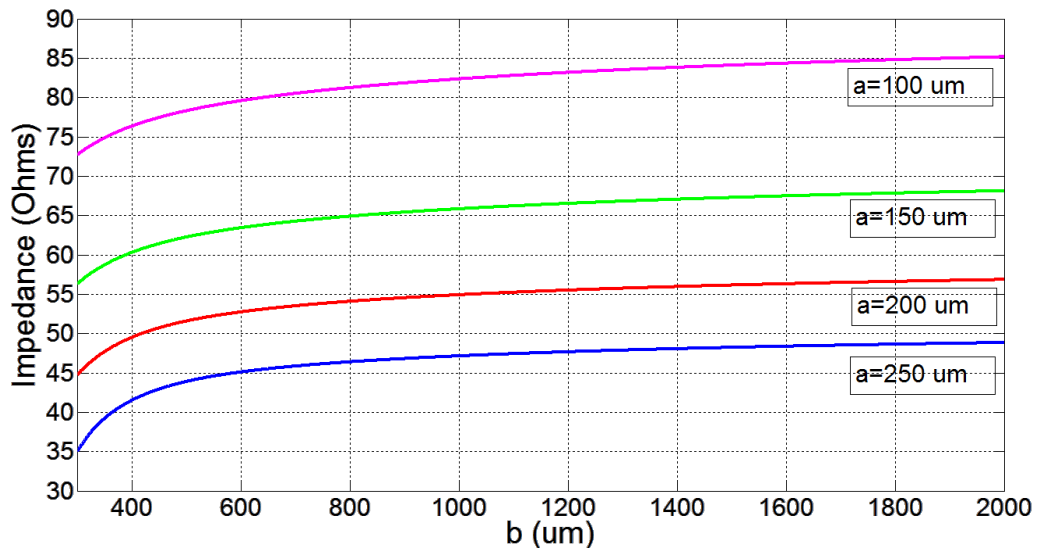

Figure 3. Waveguide impedance variations according to " $\mathrm{b}$ " ( $\mathrm{t}=40 \mu \mathrm{m}, \mathrm{h}=120 \mu \mathrm{m})$.

\subsection{Antenna Design}

The target device is a tracking system for the monitoring of elderly suffering from cognitive problems. The ISM antenna is used to ensure communication with an RF beacon implemented in the residence of the monitored person or to transmit data in the case of fugues via Sigfox network [8].

For our approach, the ground plane dimensions and form were chosen to meet the integration criteria of our research program. It will not be modified during the design and simulation process. A supplementary maximum width of $3.5 \mathrm{~mm}$ was fixed to integrate the $868 \mathrm{MHz}$ antenna as presented in Figure 4. The RF software ADS-2011 (Advanced Design System) from Keysight was chosen for this study [9].

The length of the PIFA antenna allows to set the resonance frequency and the stub dimensions determine the input impedance. For our design, a vertical direction for folding was adopted to minimize the total number of meanders. The total length of the unfolded strands is equal to $\lambda / 4=8.64 \mathrm{~cm}$. The distance between the first strand and the ground plane was set to $500 \mu \mathrm{m}$ and the various strands are characterized with a width of $250 \mu \mathrm{m}$ and spaced by a distance of $50 \mu \mathrm{m}$ from each other as presented in Figure 5. 


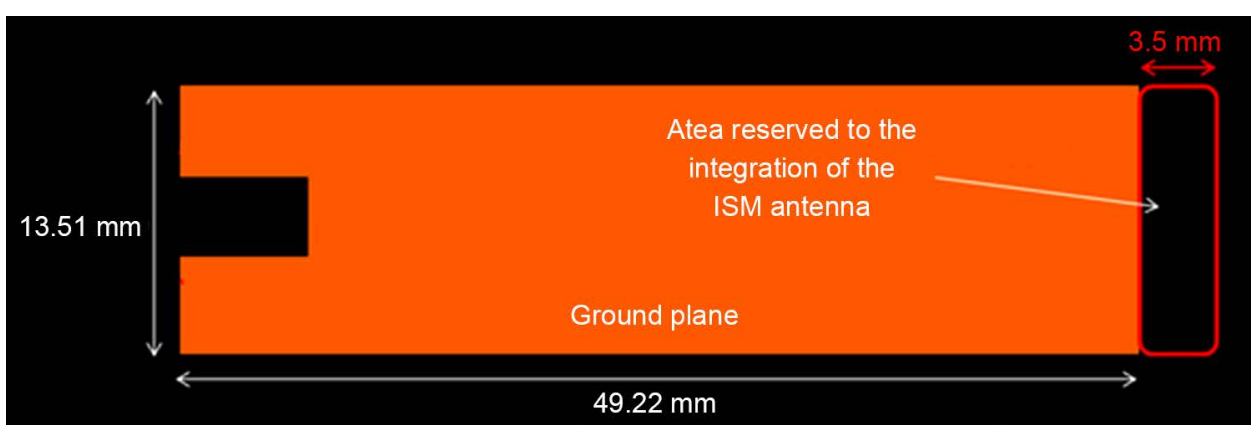

Figure 4. Integration constraints of the PIFA $868 \mathrm{MHz}$.

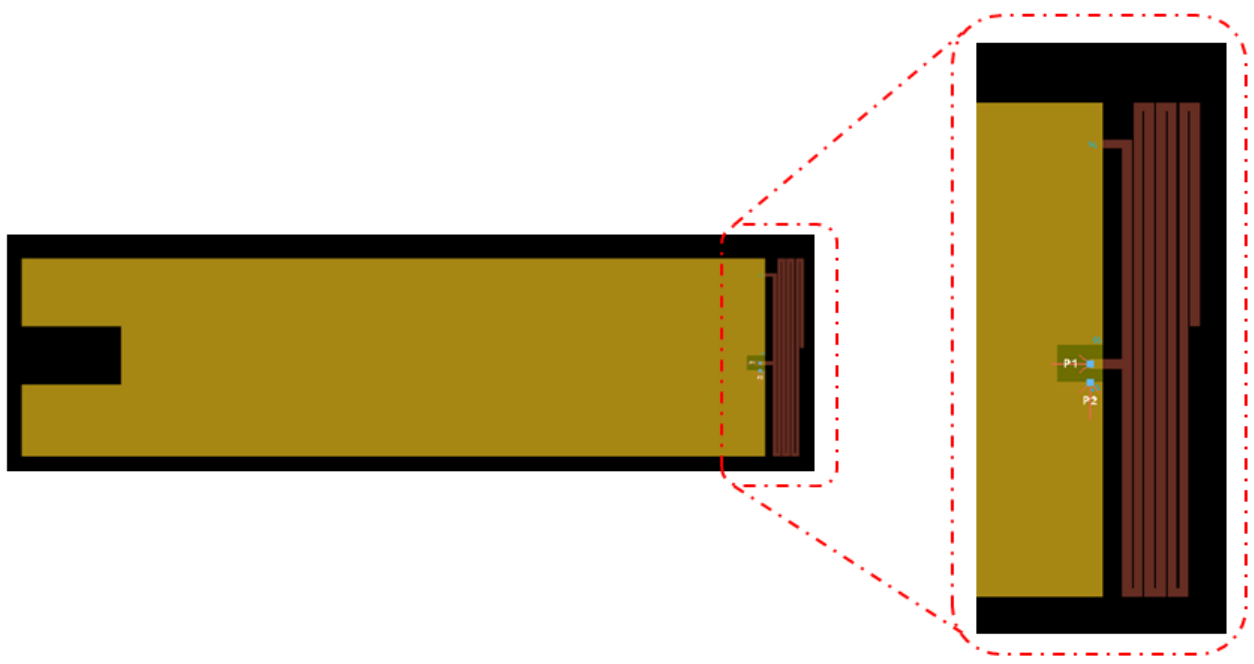

Figure 5. Initial design of the ISM antenna.

Because of the capacitive coupling between the antenna strands, the resonance frequency is higher compared with a quarter wave antenna that has the same total length of the unfolded strands. An initial resonance frequency is obtained using the design presented in Figure 5 at $2.12 \mathrm{GHz}$ as can be noticed in Figure 6.

From these results, the length of $8.64 \mathrm{~cm}$ is not adequate to obtain the target frequency and can be taken as a starting point for the radiating arm that will then be adjusted to tune the resonance frequency to $868 \mathrm{MHz}$.

To study the influence of the distance between the strands on the resonance frequency, several simulations were carried out by adjusting this distance from $50 \mu \mathrm{m}$ to $200 \mu \mathrm{m}$ while keeping the same total length of the radiating $\operatorname{arm}(8.64 \mathrm{~cm})$. The different obtained reflection coefficients are presented in Figure 7.

As can be noticed in Figure 7, when the antenna strands are closer to each other the capacitive coupling becomes stronger and the resonance frequency shifts to a higher value. To minimize this coupling and take into account the maximal width intended to the integration of the PIFA for our application, the distance between the strands was fixed to $250 \mu \mathrm{m}$. In addition to obtain the target frequency of $868 \mathrm{MHz}$ the last strand was stretched longitudinally to the ground plane. These modifications permit to adjust the antenna frequency as presented in Figure 8. 


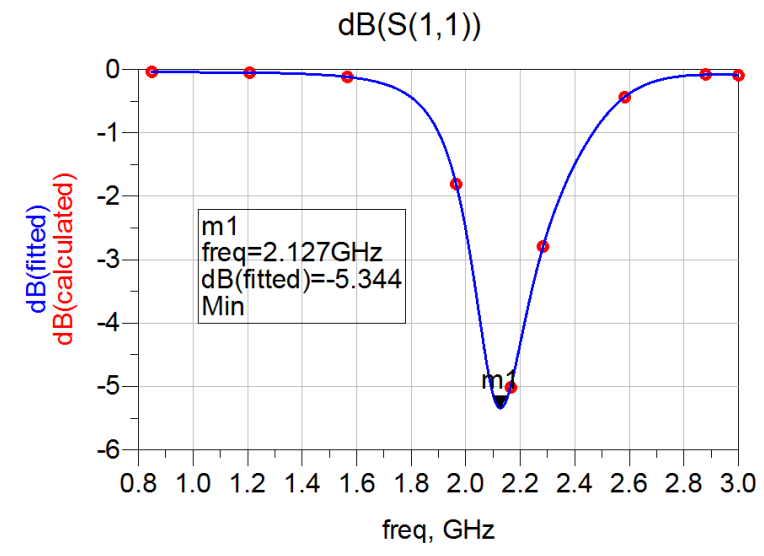

Figure 6. Reflection coefficient of the initial ISM antenna.

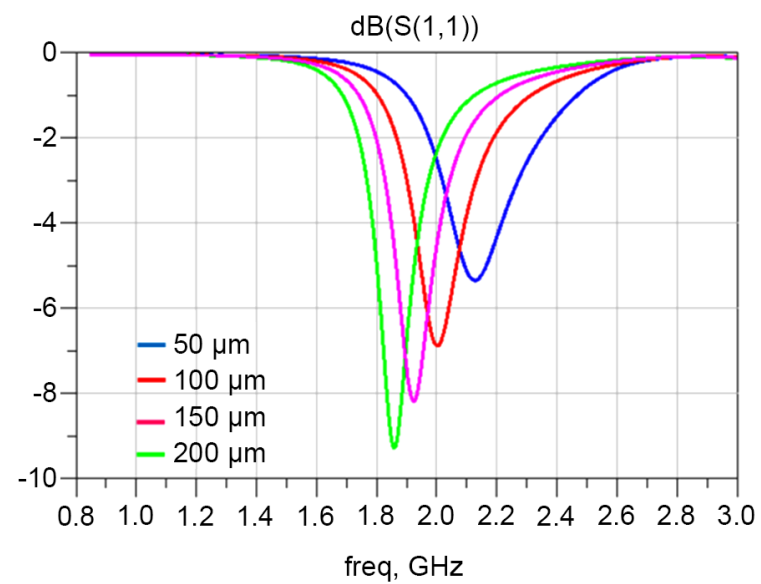

Figure 7. Influence of the distance between the strands on the resonance frequency.
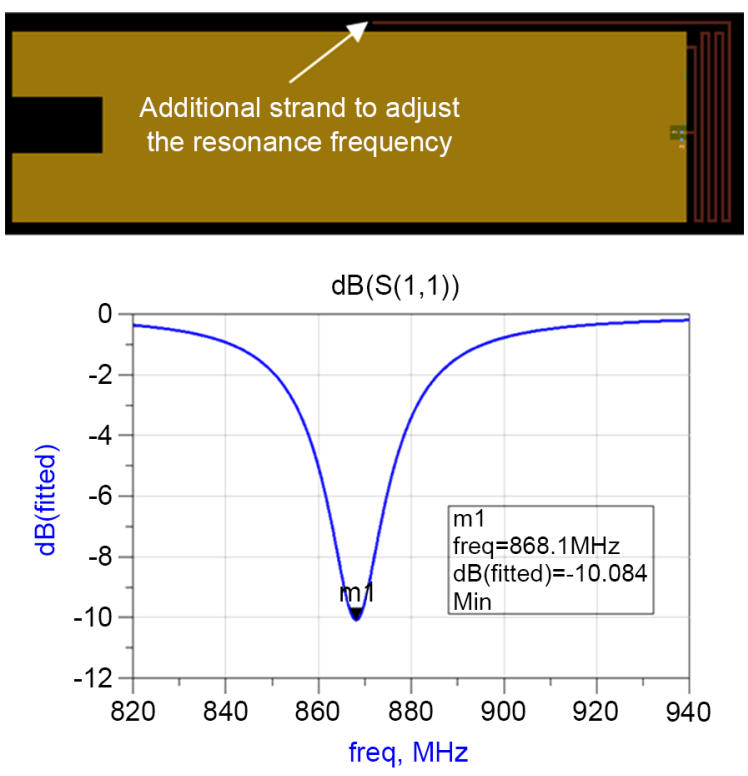

Figure 8. Adjusting the antenna resonant frequency. 
After solving the problem of the antenna length, it remains to adjust the stub for a best reflection coefficient. To do this, several simulations were conducted by modifying the distance between the supply port and the shorted point.

For the proposed antenna, the feeding point is fixed and the shorted one can be moved to vary the input impedance. The final design is presented in Figure 9.

The reflection coefficient S11 of the proposed antenna is plotted in Figure 10.

The ISM antenna has a good reflection coefficient of $-40 \mathrm{~dB}$ with a bandwidth of 6.5 $\mathrm{MHz}$.
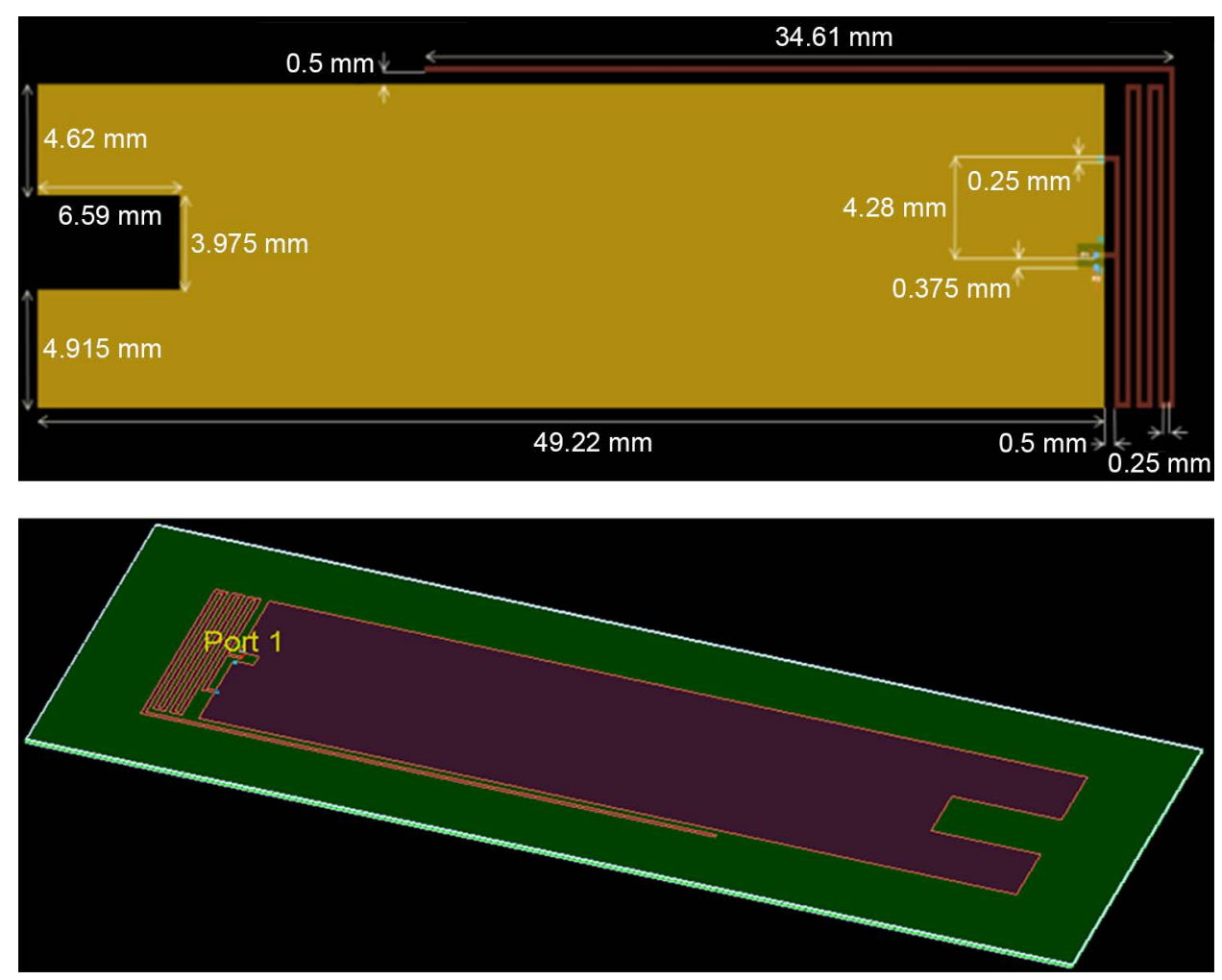

Figure 9. Final design of the ISM antenna.

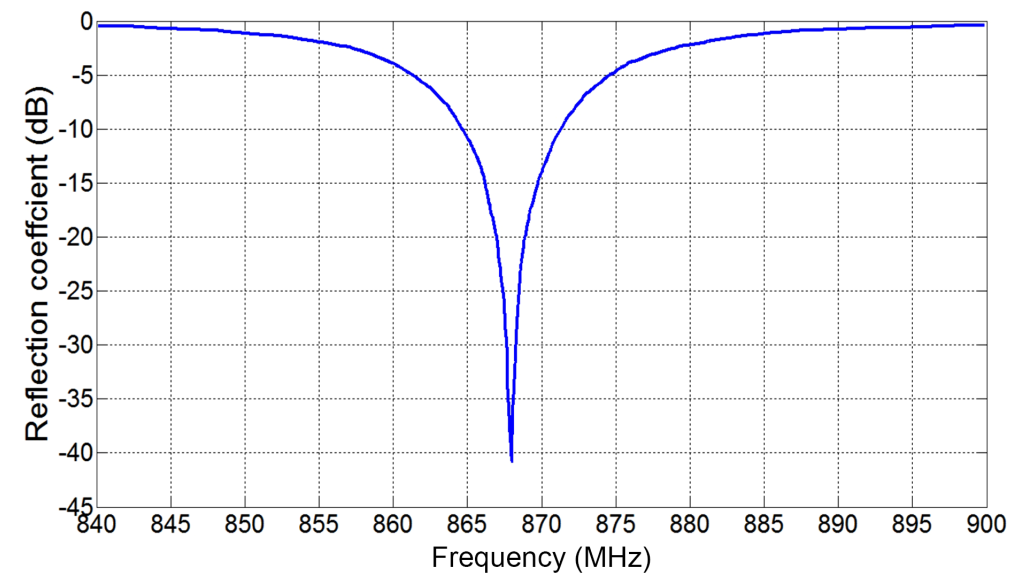

Figure 10. Reflection coefficient of the proposed $868 \mathrm{MHz}$ antenna. 


\section{Characterization and Measurement Results}

After the modeling work based on the use of ADS software, the PIFA was carried out on a FR4 substrate (Figure 11).

As our system is intended to be glued directly on the skin, an additional matching is necessary to take into account the presence of the human body effect. This is can be ensured using a Vector Network Analyzer (VNA) (Figure 12).

The measured reflection coefficient of the proposed antenna is presented in Figure 13. This antenna is characterized by a good reflection coefficient S11 of $-30 \mathrm{~dB}$ and a bandwidth of $15 \mathrm{MHz}$.

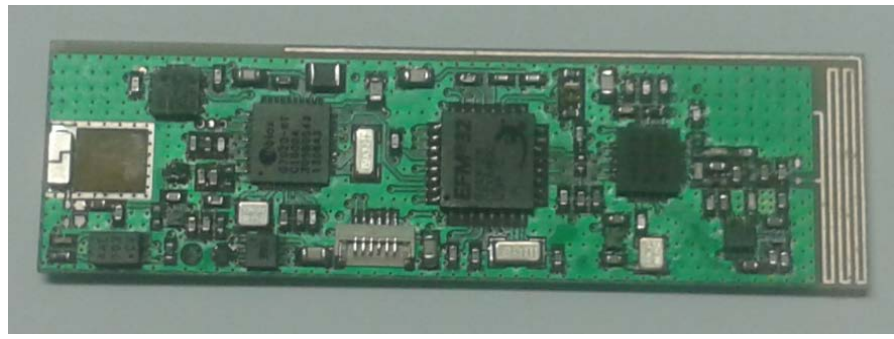

Figure 11. Prototype of the tracking device with the integrated PIFA.

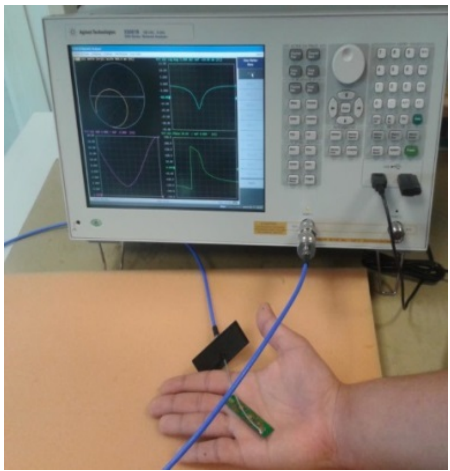

Figure 12. Reflection coefficient characterization using a VNA.

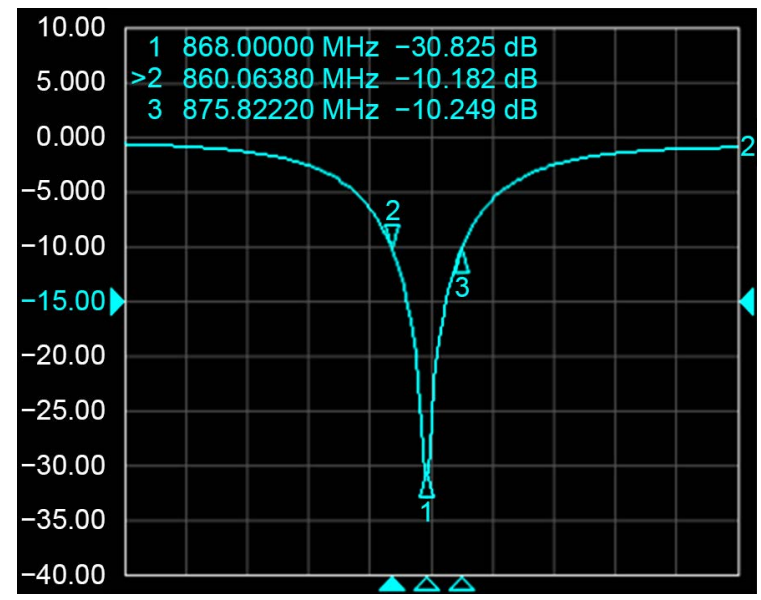

Figure 13. Measured reflection coefficient of the proposed PIFA. 


\section{Generalization}

The design approach presented in this paper can be generalized to design a meandered printed inverted $\mathrm{F}$ antenna. After the choosing of the target frequency, the waveguide can be dimensioned to ensure an impedance of $50 \Omega$. After that, the ground plane form and the area reserved to the integration of the antenna are fixed. The direction of the strands meandering is then chosen and the distance between them is set to the maximal possible value to minimize the capacitive coupling. An initial total length of $\lambda / 4$ can be chosen for the antenna and then will be adjusted to obtain the target frequency before modifying the stub form to ameliorate the reflection coefficient. These steps are detailed in the flowchart presented in Figure 14.

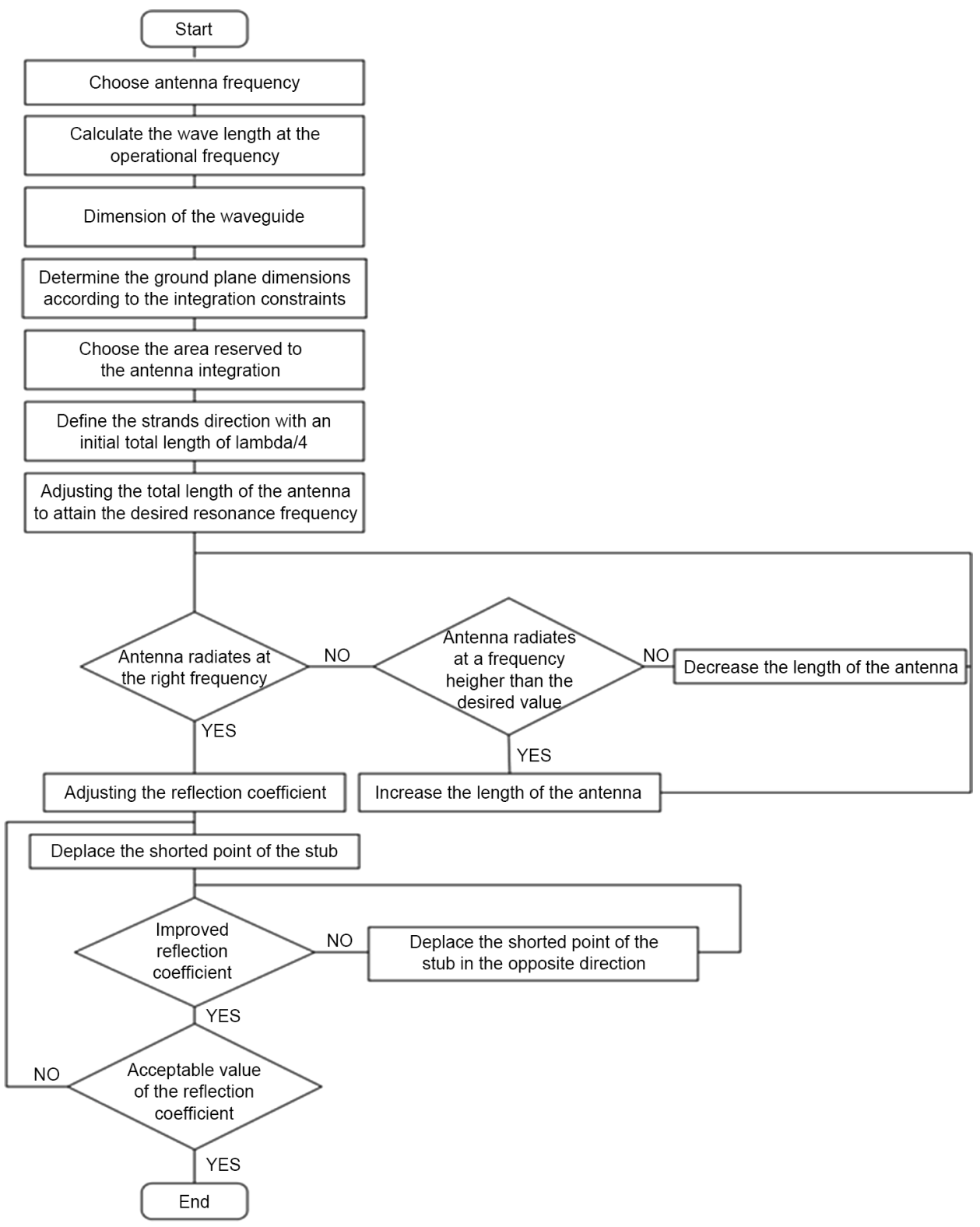

Figure 14. Design steps of a meandered PIFA. 


\section{Conclusion}

This paper presents a methodological approach to design a meandered printed inverted $\mathrm{F}$ antenna. This method was explained using an ISM $868 \mathrm{MHz}$ printed antenna integrated in a tracking device for elderly suffering from cognitive problems. The design methodology was described based on the use of the RF simulation software ADS to be adapted to any form of meandered PIFA. The RF model reference was cited only for the design of the coplanar waveguide that still unchanged for any antenna type. In our studies, we detailed the various constraints and parameters that must be taken into consideration such as the influence of the capacitive coupling between meanders on the antenna resonance frequency. This approach can be used as a guide and can be generalized for the simulation, design and integration of a meandered PIFA.

\section{Acknowledgements}

This work is part of SACHA project funded by French government and "Région Midi Pyrénées" in France. The partners of the project are Sigfox, Axible, Telecom Design companies, esanté and CHIVA hospital.

\section{References}

[1] Conway, G.A. and Scanlon, W.G. (2014) Compact Low-Profile Antenna for Wireless Medical Vital Sign Monitors at $868 \mathrm{MHz}$. The 8th European Conference on Antennas and Propagation (EuCAP 2014), The Hague, 6-11 April 2014, 830-832. http://dx.doi.org/10.1109/EuCAP.2014.6901890

[2] Jeon, J., Jang, K., Kahng, S. and Park, C. (2014) Design of a Miniaturized UHF-Band Zigbee Antenna Applicable to the M2M/IoT Communication. 2014 IEEE Antennas and Propagation Society International Symposium (APSURSI), Memphis, TN, 6-11 July 2014, 382-383. http://dx.doi.org/10.1109/APS.2014.6904523

[3] Grković, S.B. (2014) Small Balanced Antennas for Bluetooth Applications. 17th IEEE Mediterranean Electrotechnical Conference, Beirut, 13-16 April 2014, 91-96. http://dx.doi.org/10.1109/melcon.2014.6820513

[4] Amit, S. (2016) Design of Compact Bent Dipole Antenna and Its Array with High Gain Performance for GPS Application. 8th International Conference on Communication Systems and Networks (COMSNETS), Bangalore, 5-10 January 2016, 1-6.

[5] Noordin, N.H., Yan Chiew, W., Erdogan, A.T., Flynn, B. and Arslan, T. (2012) Meandered Inverted-F Antenna for MIMO Mobile Devices. Loughborough Antennas and Propagation Conference (LAPC), Loughborough, 12-13 November 2012, 1-4.

http://dx.doi.org/10.1109/lapc.2012.6402948

[6] Loizou, L., Buckley, J., Belcastro, M., Barton, J., O’Flynn, B. and O’Mathuna, C. (2013) Miniaturized Inverted-F Antenna with Capacitive Loading. 7 th European Conference on Antennas and Propagation (EuCAP), Gothenburg, 8-12 April 2013, 3213-3216.

[7] Simons, R.N. (2004) Coplanar Waveguide Circuits, Components, and Systems. John Wiley \& Sons.

[8] Hajjine, B., Escriba, C., Campo, E., Zedek, S., Acco, P., Soto Romero, G., Hemeryck, A. and Fourniols, J.-Y. (2015) Development of an Electronic Patch for Falls Detection and Elderly 
Tracking. International Conference on Biomedical and Health Informatics (ICBHI), Haikou, 9-10 October 2015.

[9] ADS. http://www.keysight.com/en/pc-1297113/advanced-design-system-ads?cc=FR\&lc=fre

Submit or recommend next manuscript to SCIRP and we will provide best service for you:

Accepting pre-submission inquiries through Email, Facebook, LinkedIn, Twitter, etc.

A wide selection of journals (inclusive of 9 subjects, more than 200 journals)

Providing 24-hour high-quality service

User-friendly online submission system

Fair and swift peer-review system

Efficient typesetting and proofreading procedure

Display of the result of downloads and visits, as well as the number of cited articles

Maximum dissemination of your research work

Submit your manuscript at: http://papersubmission.scirp.org/

Or contact ojapr@scirp.org 